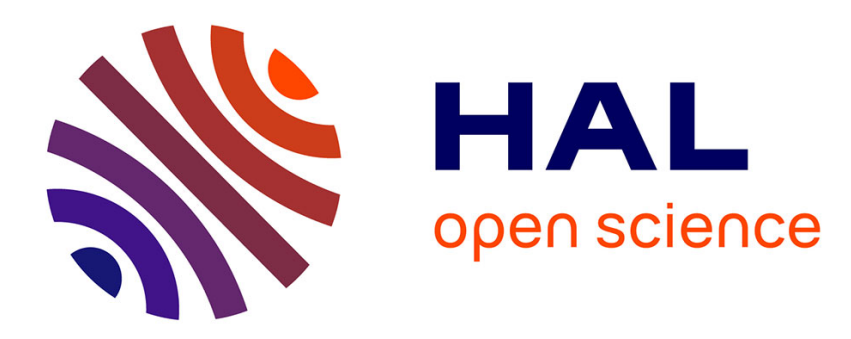

\title{
Terpyridinebenzaldehyde isomers: One-pot facile synthesis
}

Abdelaziz Jouaiti

\section{To cite this version:}

Abdelaziz Jouaiti. Terpyridinebenzaldehyde isomers: One-pot facile synthesis. Synthetic Communications, 2021. hal-03216331

\section{HAL Id: hal-03216331 \\ https://hal.science/hal-03216331}

Submitted on 3 May 2021

HAL is a multi-disciplinary open access archive for the deposit and dissemination of scientific research documents, whether they are published or not. The documents may come from teaching and research institutions in France or abroad, or from public or private research centers.
L'archive ouverte pluridisciplinaire HAL, est destinée au dépôt et à la diffusion de documents scientifiques de niveau recherche, publiés ou non, émanant des établissements d'enseignement et de recherche français ou étrangers, des laboratoires publics ou privés. 


\title{
Terpyridinebenzaldehyde isomers: One-pot facile synthesis
}

\author{
Abdelaziz Jouaiti ${ }^{a}$ \\ a Synthèse et Fonctions des Architectures Moléculaires, University of Strasbourg, CNRS, CMC UMR7140, F-67000, Strasbourg, France.
}

\begin{abstract}
We have explored the use of (Diethoxymethyl)benzaldehyde readily available as a starting material allowing us to end up with Terpyridinebenzaldehyde isomers. An environmentally friendly procedure was undertaken for the synthesis of a series of 4,3 and $2-\left(\left[2,2^{\prime}: 6^{\prime}, 2\right.\right.$ ' terpyridin]-4 ' -yl)benzaldehyde isomers (para, meta and ortho position). These compounds have been synthesized in one-pot conditions using ethanol and aqueous ammonia as solvents, at room temperature. This methodology offers substantial advantages with respect to its simplicity of operation, reaction time, satisfying yield of products and easy work-up procedure under mild reaction conditions. Apart from spectroscopic characterization, the structure of one of the Terpyridinebenzaldehyde derivative is confirmed by single-crystal X-ray diffraction.
\end{abstract}

Key words: One-pot, Terpyridine, (Diethoxymethyl)benzaldehyde, Terpyridinebenzaldehyde.

\section{Introduction}

Supramolecular chemistry, in particular the self-assembly of functional structures in metallosupramolecular architectures based on the use of transition metals and suitable ligands, has been a very active area of research in the recent decades. ${ }^{[1-3]}$.The use of functionalized "metallaligands" as "molecular bricks" is a simple way to form sophisticated molecular architectures, based on weak interactions such as hydrogen or covalent bonds like with imines. In this context, $2,2^{\prime} ; 6^{\prime}, 2^{\prime \prime}$-terpyridine and its functionalized derivatives have been widely used in the field of coordination and supramolecular chemistry to form "metallaligand", for example. ${ }^{[4]}$.Their remarkably high binding affinity towards most transition-metal ions and their chelation properties make terpyridine derivatives highly attractive building blocks for the construction of complex metallosupramolecular systems [5-10]. Coordination complexes with functionalized terpyridines are used in catalysis, ${ }^{[11-13]}$ photochemistry, ${ }^{[14-16]}$ medical chemistry ${ }^{[17-19]}$ and dye sensitized solar cells. ${ }^{[20-24]}$

Along this line, it seems interesting to develop an easy synthesis for such terpyridine derivatives. Thus, we became interested in aldehydes because they are versatile reagents in organic synthesis and, especially aromatic aldehydes, have been extensively used as starting reagents for various imine reactions to synthesize supramolecular architectures. ${ }^{[25-28]}$

CONTACT: jouaiti@unistra.fr address: Synthèse et Fonctions des Architectures Moléculaires, University of Strasbourg, CNRS, CMC UMR7140, F-67000, Strasbourg, France.

Supplemental data for this article can be accessed on the publisher's website 
These efforts led to the development of a synthetic method for ligands of the terpyridine family, $\mathbf{L} \mathbf{1}, \mathbf{L} \mathbf{2}$ and $\mathbf{L} \mathbf{3}$, bearing benzaldehyde derivative groups (Figure 1).

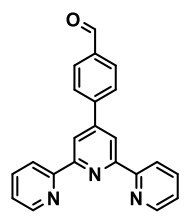

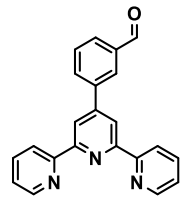

L2

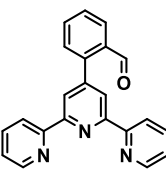

Figure 1: Terpyridinebenzaldehyde derivatives $\mathbf{L} \mathbf{1}, \mathbf{L} 2$ and $\mathbf{L} 3$

In the literature, two types of synthetic strategies have been reported for the synthesis of $4-\left(\left[2,2^{\prime}: 6^{\prime}, 2\right.\right.$ ' -terpyridin]-4 ' -yl)benzaldehyde L1 and one for 3-([2, 2' :6', 2"-terpyridin]-4'-yl)benzaldehyde L2. First, L1 has been prepared in four steps (Scheme 1, (a)). ${ }^{[29]}$ The last step reaction of this pathway is based on the palladium-catalysed cross-coupling of 4' -triflate-terpyridine with 4-formylphenylboronic acids, with an overall yield of $6 \%$.

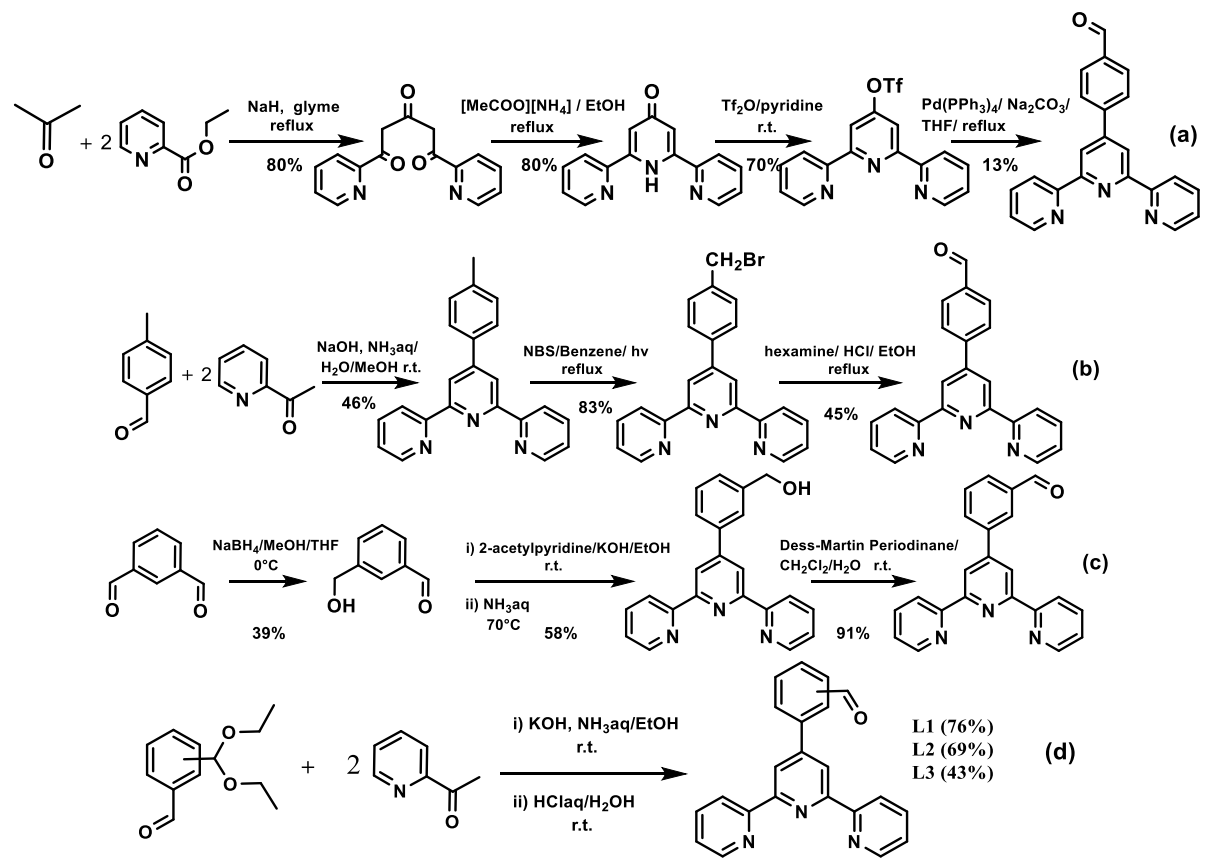

Scheme 1. : Conventional Methods : (a) and (b) reported for the preparation of 4-([2,2' $: 6^{\prime}, 2$ " -terpyridin]-4 ' -yl)benzaldehyde; (c) for the preparation of $3-\left(\left[2,2^{\prime}: 6^{\prime}, 2^{\prime \prime}\right.\right.$-terpyridin $\left.]-4^{\prime}-y l\right)$ benzaldehyde; (d) the one-pot strategy developed herein (this work).

The second synthetic approach for $\mathbf{L 1}^{\left[{ }^{[30]}\right.}$ (Scheme $\left.1,(b)\right)$ is based, in the first step, on the preparation of $4^{\prime}$-tolyl$2,2^{\prime}: 6^{\prime}, 2^{\prime \prime}-$ terpyridine followed by bromination and finally oxidation, with an overall yield of $17 \%$ yield. Concerning $\mathbf{L}$, one synthetic strategy has been recently described. ${ }^{[31]}$.This product was synthesized in three steps from isophalaldehyde with an overall yield of almost $20 \%$ (Scheme 1 (c)).

Nevertheless, there are certain limitations to these three methods: too long synthesis time, the use of expensive reagents and toxic solvents. In addition to all these drawbacks, the overall yields of these three methods is low: $6 \%, 17 \%$ and $20 \%$ respectively. 
The development of an efficient and general approach for obtaining 4-([2, 2':6', 2"-terpyridin]-4'-yl)benzaldehyde L1 or terpyridinebenzaldehyde isomers, 3-([2, 2' :6', 2'-terpyridin]-4'-yl)benzaldehyde $\mathbf{L} \mathbf{2}$ and the positional isomer 2-([2, 2' :6', 2"-terpyridin]-4'-yl)benzaldehyde L3, under metal-free conditions using a one-pot synthesis, is of overriding value and challenging. Therefore, an efficient protocol should using straightforward and readily available starting components, appears really appealing.

Herein, we report an efficient and easy method to obtain terpyridinePh-CHO (-CHO in para, meta or ortho position (L1, L2 or L3)). Indeed, these compounds have been synthesized in one-pot reactions under metal-free conditions using ethanol and water as solvents. This procedure features short reaction times, easy work-up, and good yields. Most of used starting materials are commercially available and non-expensive.

\section{Results and discussion}

The first known synthesis for terpyridine derivatives is the one reported by Kröhnke et al. in 1976 , ${ }^{[32]}$ followed by other methods such as the use of the Stille coupling, for example. ${ }^{[33]}$. But the recently reported synthetic methods ${ }^{[34-36]}$ marked a significant improvement. Indeed, the functionalized terpyridines were easily obtained via a condensation sequence of aldol and Michael addition, involving the use of solid $\mathrm{NaOH}$, followed by treatment with ammonium acetate or aqueous ammonia in a one-pot reaction, with high yield. Our strategy for obtaining $\mathbf{L} \mathbf{1}, \mathbf{L} \mathbf{2}$ or $\mathbf{L} \mathbf{3}$ is based on the adaptation of an already reported method of this synthesis, that leads to terpyridinebenzaldehyde isomers. The electrophilic nature of the carbonyl group of these compounds is a dominant feature of its possible extensive chemistry that is occurring. Here, in order to synthesize these compounds, we need a starting material containing two carbonyl groups. It is therefore necessary to protect one carbonyl that we would like to find at the end of synthesis, from a nucleophilic attack. The use of readily available (diethoxymethyl) benzaldehyde seems perfectly suitable, since one carbonyl will undergo a nucleophilic attack to synthesize the terpyridine moiety while the other carbonyl is protected against this attack. ${ }^{[37]}$ This proposed strategy allows to generate the carbonyl at the end of the reaction and therefore to have access to benzaldehyde moiety. A mild and easy regeneration of the carbonyl compounds from their resulting 1,1-diacetals has been carried out. Indeed, these acetals easily undergo deacetalization to yield terpyridinebenzaldehyde isomers, under acidic conditions at room temperature.

The proposed synthetic pathways, for the synthesis of L1, L2 and L3, considering this strategy, are presented in Scheme 1 (d) and Scheme 2. The required starting compounds, 3 and 4-(diethoxymethyl)benzaldehyde isomers, are commercially available. The 2-(diethoxymethyl)benzaldehyde is easily prepared by lithiation of commercially available 2 - 
bromo-(diethoxymethyl)benzene with $n$-BuLi at $-70{ }^{\circ} \mathrm{C}$ and subsequent treatment with DMF, as described in the literature. ${ }^{[38,39]}$

For the synthesis of L1, L2 and L3, we adopted two strategies: the first one, (Scheme 2), is based on separating the diacetalterpyridine derivatives as intermediate products before reaching the targeted products. The second strategy (Scheme $1(d))$ is under one-pot conditions.

The two-step synthesis (Scheme 2 see ESI for experimental details) of the terpyridinebenzaldehyde isomers begins by mixing 2-acetylpyridine and different (diethoxymethyl)benzaldehyde precursors in ethanol in 2:1 molar ratio in the presence of $\mathrm{KOH}$ pellets and $\mathrm{NH}_{3}$ aqueous solution. The reaction is completed by stirring the mixture at room temperature overnight. After reducing the volume, the mixture is extracted with ethyl acetate and purified by short column chromatography affording the desired (diethoxymethyl)benzaldehyde derivatives $\mathbf{1}, \mathbf{2}$ and $\mathbf{3}$ in $86 \%$, 83\% and 50\% respectively. In the second step, a dilute $\mathrm{HCl}$ solution is added to deprotect the aldehyde; neutralizing the medium allows to obtain the desired aldehyde products $\mathbf{L} \mathbf{1}, \mathbf{L} \mathbf{2}$ and $\mathbf{L} \mathbf{3}$ in $91 \%, 86 \%$ and $73 \%$ yield respectively.

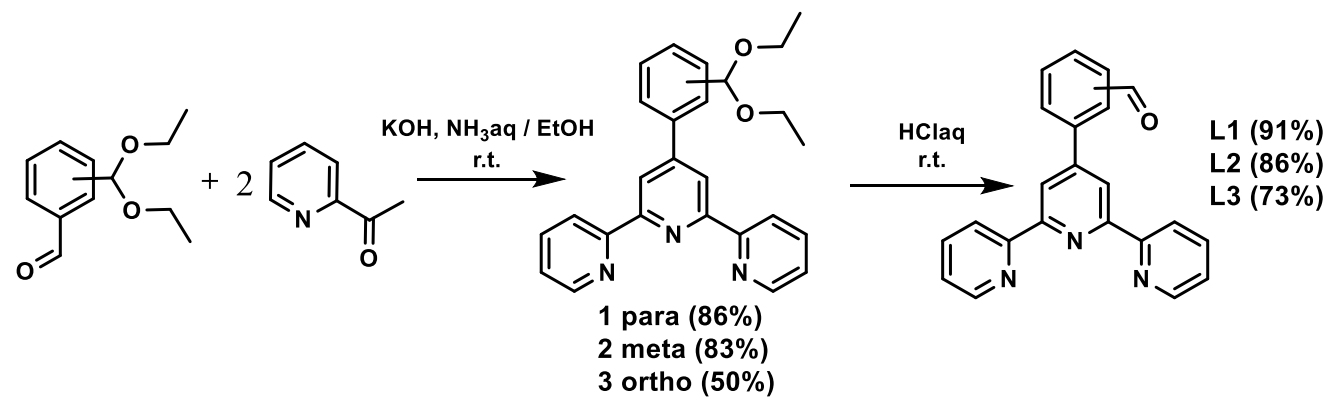

Scheme 2. : Two steps synthetic pathway for the obtention of L1, L2 and L3

The one-pot approach (Scheme $1(d))$ is based on the use of the reactivity profile in the basic medium of protected benzaldehydes, in order to achieve the targeted products. (Diethoxymethyl)benzaldehyde (para, meta or ortho) is added to 2-acetylpyridine in ethanol in 2:1 molar ratio (see ESI for experimental details), in the presence of $\mathrm{KOH}$ pellets and $\mathrm{NH}_{3}$ aqueous solution. To the mixture, a dilute $\mathrm{HCl}$ solution is added, neutralizing the medium and allowing us to obtain the desired aldehyde products $\mathbf{L} \mathbf{1}, \mathbf{L} \mathbf{2}$ and $\mathbf{L} \mathbf{3}$ in 76\%, 69\% and $43 \%$ yield respectively. The yield of the two synthesis methods are slightly similar (see Table below)

Isolated yield (\%) : two step synthesis method

Isolated yield (\%) : one-pot synthesis method
L1

$78 \%$,

$76 \%$,

$69 \%$
L3

$36 \%$ $43 \%$ 
Table : Comparison of the results of both synthetic methods.

In addition to their spectroscopic data (see ESI for characterization details), the structure of L3 has been confirmed by single crystal X-ray diffraction studies in the solid state (Figure 2). Single crystals suitable for X-ray diffraction analysis have been obtained for $\mathbf{L} 3$, so far by slow evaporation of a $\mathrm{CHCl}_{3} / \mathrm{EtOH}$ solution at room temperature (see the ESI for crystallographic data, CCDC 2018232 (L3)). The compound crystallizes in the monoclinic space group, P 21/n. The C = C, C

- C, C-N, C = N and C = O distances are within the expected range for this type of covalent bonds $(d=1.208-1.493 \AA)$. The three pyridine groups are almost coplanar. The benzaldehyde group is not coplanar with the central pyridine, but tilted by $-46.87^{\circ}$.

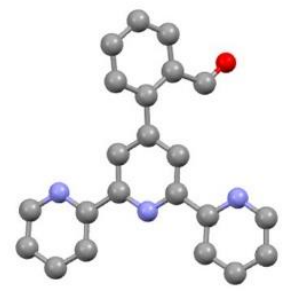

Figure 2: Single crystal X-ray structure of L3. Hydrogen atoms are omitted for the sake of clarity.

\section{Conclusions}

The use of (diethoxymethyl)benzaldehyde as a readily available starting material allowed us to obtain three terpyridinebenzaldehyde isomer derivatives. This methodology offers substantial advantages with respect to its simplicity of operation, availability of starting materials, reaction times, yield of products and easy work-up procedure under mild reaction conditions. These significant features are expected to contribute to the development of a green strategy for the synthesis of new terpyridinebenzaldehyde derivatives and subsequently to novel metallosupramolecular architectures.

\section{Experimental section}

\section{a) General method for the synthesis of the Terpyridinebenzaldehyde isomer L1.}

To a solution of 2-Acetylpyridine $(1.16 \mathrm{~g}, 9.5 \mathrm{mmol})$, potassium hydroxide $(0.54 \mathrm{~g}, 9.6 \mathrm{mmol})$ and the corresponding (Diethoxymethyl)benzaldehyde in $10 \mathrm{~mL}$ of absolute ethanol $(1 \mathrm{~g}, 4.8 \mathrm{mmol})$, were added $12 \mathrm{~mL}$ of $32 \%$ aqueous ammonia solution. The mixture was stirred overnight at room temperature. The reaction volume was reduced by half, then $15 \mathrm{ml}$ of a $15 \%$ aqueous $\mathrm{HCl}$ solution were added. After $3 \mathrm{~h}$ at room temperature, the solution was neutralized by a $10 \%$ aqueous $\mathrm{K}_{2} \mathrm{CO}_{3}$ solution. The mixture was extracted with dichloromethane $(3 \times 30 \mathrm{~mL})$. The combined organic layer was dried with $\mathrm{Na}_{2} \mathrm{SO}_{4}$, filtered and the solvent was removed under reduced pressure. The aldehyde phenyl-Terpyridne derivatives $\mathbf{L 1}$ 
was obtained as a white solid by washing the crude product with methanol in $76 \%$ yield. If necessary, the crude product was purified by a short column chromatography $\left(\mathrm{Al}_{2} \mathrm{O}_{3}\right.$, eluant, ethyl acetate/cyclohexane 1:1). Note, to make a pure product, it's necessary to wash with $\mathrm{MeOH}$.

Compound L1: white solid, $1.2 \mathrm{~g}, 76 \%$ yield, $\mathrm{mp}=195^{\circ} \mathrm{C}$.

${ }^{1} \mathrm{H}-\mathrm{NMR}\left(\mathrm{CDCl}_{3}, 300 \mathrm{MHz}\right): \delta(\mathrm{ppm})=7.37\left(\mathrm{ddd}, j_{1}=1.5 \mathrm{~Hz}, j_{2}=5 \mathrm{~Hz}, j_{3}=7.5 \mathrm{~Hz}, 2 \mathrm{H}\right), 7.89(\mathrm{td}, j=7.5 \mathrm{~Hz}, 1 \mathrm{H}), 8.04(\mathrm{~m}, 4 \mathrm{H}), 8.68$ (d, $\left.j_{1}=8.1 \mathrm{~Hz}, 2 \mathrm{H}\right), 8.74(\mathrm{~m}, 2 \mathrm{H}), 8.77(\mathrm{~s}, 2 \mathrm{H}), 10.10(\mathrm{~s}, 1 \mathrm{H})$.

${ }^{13} \mathrm{C}-\mathrm{NMR}\left(\mathrm{CDCl}_{3}, 75 \mathrm{MHz}\right): \delta(\mathrm{ppm})=191.9,156.0,155.7,149.0,148.9,144.4,137.1,136.4,130.3,128.1,124.1,121.5$, 119.1

Elemental analysis (\%) for $\mathrm{C}_{22} \mathrm{H}_{15} \mathrm{~N}_{3} \mathrm{O}$, calculated: $\mathrm{C}, 78.32 ; \mathrm{H}, 4.48 ; \mathrm{N}, 12.46$; found: $\mathrm{C}, 78.36 ; \mathrm{H}, 4.54 ; \mathrm{N}, 12.40$.

Full experiment details, characterization data $\left({ }^{1} \mathrm{H} N M R,{ }^{13} \mathrm{C}\right.$ NMR spectra and elemental analysis) and copies of ${ }^{1} \mathrm{H}$ NMR and ${ }^{13} \mathrm{C}$ NMR spectra are included in the Supplementary material. CIF data of compound (L3) is deposited in Cambridge Crystallographic Data CentreCenter (CCDC) and its CCDC number: 2018232. The data is available free of charge at http://www.ccdc.cam.ac.uk.

\section{Acknowledgments}

Thanks to N. Kyritsakas for the structural analysis Prof. S. Ferlay and S. Baudron for proofreading. The Université de Strasbourg and CNRS are acknowledged for financial support.

\section{References}

[1] Chen, L-J.; Yang, H-B.; Shionoya, M. Chiral metallosupramolecular architectures. Chem. Soc. Rev. 2017, 46, 25552576. DOI: $10.1039 / C 7 C S 00173 H$

[2] G.-Y Wu, L-J. Chen, L. Xu, X-L. Zhao, H-B. Yang, Construction of supramolecular hexagonal metallacycles via coordination-driven self-assembly: Structure, properties and application. Coord. Chem. Rev. 2018, 369, 39-75. DOI: 10.1016/j.ccr.2018.05.009.

[3] Gan, M-M. ; Liu, J-Q. ; Zhang, L. ; Wang, Y-Y. ; Hahn, F. E. ; Han, Y-F. Preparation and Post-Assembly Modification of Metallosupramolecular Assemblies from Poly(N-Heterocyclic Carbene) Ligands. Chem. Rev. 2018, 118, 9587-9641. DOI: 10.1021/acs.chemrev.8b00119.

[4] Housecroft, C. E.; Constable, E. C. The terpyridine isomer game: from chelate to coordination network building block. Chem. Commun. 2020, 56, 10786-10794. DOI: 10.1039/d0cc04477f. 
[5] Chakraborty, S.; Newkome, G. R. Terpyridine-based metallosupramolecular constructs: tailored monomers to precise 2D-motifs and 3D-metallocages. Chem. Soc. Rev. 2018, 47, 3991-4016. DOI: 10.1039/C8CS00030A.

[6] Schwarz, G.; Haßlauer, I.; Kurth, D. G. From terpyridine-based assemblies to metallo-supramolecular polyelectrolytes (MEPEs). Adv Colloid Interface Sci. 2014, 207, 107-120. DOI: 10.1016/j.cis.2013.12.010.

[7] Song, B.; Kandapal, S.; Gu, J.; Zhang, K.; Reese, A., Ying, Y., Wang, L.; Wang, H.; Li, Y.; Wang, M.; Lu, S.; Hao, XQ.; Li, X. G.; Xu, B.; Li, X. Self-assembly of polycyclic supramolecules using linear metal-organic ligands. Nat Commun, 2018, 9, 4575-4583. DOI: 10.1038/s41467-018-07045-9.

[8] Fu, J-H.; Wang, S-Y.; Chen, Y-S.; Prusty, S.; Chan, Y-T. One-Pot Self-Assembly of Stellated Metallosupramolecules from Multivalent and Complementary Terpyridine-Based Ligands. J. Am. Chem. Soc. 2019, 141, 16217-16221. DOI: 10.1021/jacs.9b08731.

[9] Wang, S-Y.; Huang, J-Y.; Liang, Y-P.; He, Y. J.; Chen Y-S.; Zhan, Y-Y.; Hiraoka, S.; Liu, Y-H.; Peng, S-M.; Chan, Y-T. Multicomponent Self-Assembly of Metallo-Supramolecular Macrocycles and Cages through Dynamic Heteroleptic Terpyridine Complexation. Chem. Eur. J. 2018, 24, 9274-9284. DOI: 10.1002/chem.201801753.

[10] Ziener, U.; Breuning, E.; Lehn, J.-M.; Wegelius, E.; Rissanen, K.; Baum, G.; Fenske, D.; Vaughan, G. RecognitionDirected Supramolecular Assemblies of Metal Complexes of Terpyridine Derived Ligands with SelfComplementary Hydrogen Bonding Sites. Chem. Eur. J. 2000, 6, 4132-4139. DOI: 10.1002/15213765(20001117)6:22<4132::AID-CHEM4132>3.0.CO;2-W.

[11] Zhang, G.; Zeng, H.; Li, S.; Johnson, J.; Mo, Z., Neary, M. C.; Zheng, S. 1-D manganese(ii)-terpyridine coordination polymers as precatalysts for hydrofunctionalisation of carbonyl compounds. Dalton Trans. 2020, 49, 2610-2615. DOI: 10.1039/C9DT04637B.

[12] Kwong, H-L.; Wong, W-L.; Lee, W-S.; Cheng, L.-S.; Wong, W-T. New chiral 2,2':6', $2^{\prime \prime}$-terpyridine ligands from the chiral pool: synthesis, crystal structure of a rhodium complex and uses in copper- and rhodium-catalyzed enantioselective cyclopropanation of styrene. Tetrahedron Asymmetry, 2001, 12, 2683-2694. DOI: 10.1016/S0957-4166(01)00431-1.

[13] Zhang, Y.; Sun, X.; Zhang, H.; Zhao, J. Immobilization of Ru(terpyridine)(2,6-pyridinedicarboxylate) onto MCM41 and its catalysis in the oxidation of alcohols. Appl. Organometal. Chem., 2016, 30, 645-652. DOI: 10.1002/aoc.3484. 
[14] Schofield, E. R.; Collin, J-P.; Gruber, N.; Sauvage, J-P. Photochemical and thermal ligand exchange in a ruthenium(ii) complex based on a scorpionate terpyridineligand. Chem. Commun. 2003, 188-189. DOI: 10.1039/B210607H.

[15] Labra-Vázquez, P.; Bocé, M.; Tassé, M. ; Mallet-Ladeira, S.; Lacroix, P. G.; Farfán, N.; Malfant, I. Chemical and photochemical behavior of ruthenium nitrosyl complexes with terpyridine ligands in aqueous media. Dalton Trans. 2020, 49, 3138-3154. DOI: 10.1039/C9DT04832D.

[16] Jang, C. K.; Lee, Y. H.; Han, S. Y.; Jaung, J. Y. The synthesis and optical characterization of quinoxalines bearing 2,2':6',2"-terpyridine. Dyes and Pigments, 2008 79, 101-104. DOI: 10.1016/j.dyepig.2007.10.012.

[17] Rajalakshmi, S.; Weyhermüller, T.; Dinesh, M.; Nair, B. U. Copper(II) complexes of terpyridine derivatives: A footstep towards development of antiproliferative agent for breast cancer. J. Inorg. Biochem, 2012, 117, 48-59. DOI: 10.1016/j.jinorgbio.2012.08.010.

[18] Liang, X.; Jiang, J.; Xue, X.; Huang, L.; Ding, X.; Nong, D.; Chen, H.; Pan, L.; Ma, Z. Synthesis, characterization, photoluminescence, anti-tumor activity, DFT calculations and molecular docking with proteins of zinc(ii) halogen substituted terpyridine compounds. Dalton Trans. 2019, 48, 10488-10504. DOI: 10.1039/C8DT04924F.

[19] Hahn, E. M.; Estrada-Ortiz, N.; Han, J.; Ferreira, V. F. C. ; Kapp, T. G.; Correia, J. D. G.; Casini, A.; Kühn, F. E. Functionalization of Ruthenium(II) Terpyridine Complexes with Cyclic RGD Peptides To Target Integrin Receptors in Cancer Cells. Eur. J. Inorg. Chem. 2017, 1667-1672. DOI: 10.1002/ejic.201601094.

[20] Robson, K. C. D., Koivisto, B. D., Yella, A.; Sporinova, B.; Nazeeruddin, M. K.; Baumgartner, T.; Grätzel, M.; Berlinguette, C. P. Design and Development of Functionalized Cyclometalated Ruthenium Chromophores for Light-Harvesting Applications. Inorg. Chem. 2011, 50, 5494-5508. DOI: 10.1021/ic200011m.

[21] Ozawa, H.; Sugiura, T.; Kuroda, T.; Nozawa K.; Arakawa, H. Highly efficient dye-sensitized solar cells based on a ruthenium sensitizer bearing a hexylthiophene modified terpyridine ligand. J. Mater. Chem. A. 2016, 4, 17621770. DOI: 10.1039/C5TA10393B.

[22] Caramori, S.; Husson, J., Beley, M.; Bignozzi, C. A.; Argazzi, R.; Gros, P. C. Combination of Cobalt and Iron Polypyridine Complexes for Improving the Charge Separation and Collection in Ru(terpyridine) ${ }_{2}$-Sensitised Solar Cells. Chem. Eur. J. 2010, 16, 2611-2618. DOI: 10.1002/chem.200902761.

[23] Duchanois, T.; Etienne, T.; Cebrián, C.; Liu, L.; Monari, A.; Beley, M.; Assfeld, X.; Haacke, S; Gros, P. C. An IronBased Photosensitizer with Extended Excited-State Lifetime: Photophysical and Photovoltaic Properties. Eur. J. Inorg. Chem. 2015, 2469-2477. DOI: 10.1002/ejic.201500142. 
[24] Ozawa, H.; Fukushima, K.; Urayama, A.; Arakawa, H. Efficient Ruthenium Sensitizer with an Extended $\pi-$ Conjugated Terpyridine Ligand for Dye-Sensitized Solar Cells. Inorg. Chem. 2015, 54, 8887-8889. DOI: 10.1021/acs.inorgchem.5b01640.

[25] Qian, C., Qi, Q-Y. ; Jiang, G-F. ; Cui, F-Z.; Tian, Y.; Zhao, X. Toward Covalent Organic Frameworks Bearing Three Different Kinds of Pores: The Strategy for Construction and COF-to-COF Transformation via Heterogeneous Linker Exchange. J. Am. Chem. Soc. 2017, 139, 6736-6743. DOI: 10.1021/jacs.7b02303.

[26] Mastalerz, M. Porous Shape-Persistent Organic Cage Compounds of Different Size, Geometry, and Function. Acc. Chem. Res. 2018, 51, 2411-2422. DOI: 10.1021/acs.accounts.8b00298.

[27] Greenaway, R.L.; Santolini, V.; Bennison, M.J.; Alston, B.M.; Pugh, C.J.; Little, M.A; Miklitz, M.; Eden-Rump, E.G.B.; Clowes, R.; Shakil, A.; Cuthbertson, H.J.; Armstrong, H.; Briggs, M.E.; Jelfs, K.E.; Cooper, A.I. High-throughput discovery of organic cages and catenanes using computational screening fused with robotic synthesis. Nat. Commun. 2018, 9, 1-11. DOI: 10.1038/s41467-018-05271-9.

[28] Chen, X.; Huang, N.; Gao, J.; Xu, H.; Xu, F.; Jiang, D. Towards covalent organic frameworks with predesignable and aligned open docking sites. Chem. Commun. 2014, 50, 6161-6163. DOI: 10.1039/C4CC01825G.

[29] Goodall, W.; Wild, K.; Arm, K. J.; Williams, J. A. G. The synthesis of 4'-aryl substituted terpyridines by Suzuki crosscoupling reactions: substituent effects on ligand fluorescence. J. Chem. Soc., Perkin Trans. 2, 2002, 1669-1681. DOI: 10.1039/B205330F.

[30] Miyamoto, Y.; Kikuchi, A.; Iwahori, F.; Abe, J. Synthesis and Photochemical Properties of a Photochromic Iron(II) Complex of Hexaarylbiimidazole. J. Phys. Chem. A, 2005, 109, 10183-10188. DOI: 10.1021/jp0540306.

[31] Filosa, A.; Wang, H.; Li, W-J.; Zhang, W.; Ngo, E.; Piccolo, J. E.; Yang, H-B.; Li, X. Order from Chaos: Self-Assembly of Nanoprism from a Mixture of Tetratopic Terpyridine-Porphyrin Conformers. Chin. J. Chem. 2019, 37, 11671173. DOI: 10.1002/cjoc.201900177.

[32] Kröhnke, F. The Specific Synthesis of Pyridines and Oligopyridines. Synthesis, 1976, 1-24. DOI: 10.1055/s-197623941.

[33] Heller, M.; Schubert, U. S. Functionalized 2,2'-bipyridines and 2,2':6',2' '-terpyridines via stille-type crosscoupling procedures. J. Org. Chem. 2002, 67, 8269-8272. DOI: 10.1021/jo0260600 .

[34] Cave, G.W.V.; Raston, C. L. Toward benign syntheses of pyridines involving sequential solvent free aldol and Michael addition reactions. Chem. Commun. 2000, 2199-2200. DOI: 10.1039/B0074310. 
[35] Wang, J.; Hanan, G.S. A Facile Route to Sterically Hindered and Non-Hindered 4'-Aryl-2,2':6',2'-Terpyridines. Synlett, 2005, 1251-1254. DOI: 10.1055/s-2005-868481.

[36] Rocco, D. Housecroft, C. E. Constable, E. C. Synthesis of Terpyridines: Simple Reactions-What Could Possibly Go Wrong? Molecules, 2019, 24, 1799-1795. DOI: 10.3390/molecules24091799.

[37] Achelle, S.; Malval, J.-P.; Aloïse, S.; Barsella, A.; Spangenberg, A.; Mager, L.; Akdas-Kilig, H.; Fillaut, J.-L.; Caro, B.; Robin-le Guen, F. Synthesis, Photophysics and Nonlinear Optical Properties of Stilbenoid Pyrimidine-Based Dyes Bearing Methylenepyran Donor Groups. ChemPhysChem. 2013, 14, 2725-2736. DOI: 10.1002/cphc.201300419.

[38] Chezal, J. M.; Moreau, E.; Desbois, N. ; Blache, Y.; Chavignon, O.; Teulade, J. C. Synthesis of carbamoylpyridine and imidazo[1,5-a]pyridin-1,3-diones via ortho-acetalhydantoin intermediates. Tetrahedron Letters, 2004, 45, 553-556. DOI: 10.1016/j.tetlet.2003.10.200.

[39] Ueda, M.; Kawai, S.; Hayashi, M.; Naito, T.; Miyata, O. Efficient Entry into 2-Substituted Tetrahydroquinoline Systems through Alkylative Ring Expansion: Stereoselective Formal Synthesis of ( \pm )-Martinellic Acid. J. Org. Chem. 2010, 75, 914-921. DOI : 10.1021/jo902540x. 